TAVARES, H.L.; JUNQUEIRA, A.M. R. Produção hidropônica de alface cv. Verônica em diferentes substratos. Horticultura Brasileira, Brasília, v. 17, n. 3, p. 240-243, novembro 1999 .

\title{
Produção hidropônica de alface cv. Verônica em diferentes substratos ${ }^{1}$.
}

Helton L. Tavares; Ana Maria R. Junqueira ${ }^{2}$

${ }^{2}$ Universidade de Brasília - Faculdade de Agronomia e Medicina Veterinária - Núcleo de Apoio à Competitividade e Sustentabilidade da Agricultura, Caixa Postal 4.508, 70910-970, Brasília-DF.

\section{RESUMO}

Em um experimento realizado na Fazenda Água Limpa da Universidade de Brasília, (DF), no período de setembro a novembro de 1997, foi avaliado o desempenho da alface, cultivar Verônica, em diferentes substratos, sob cultivo hidropônico. O delineamento utilizado foi inteiramente casualizado com três tratamentos: casca de arroz, brita e seixo, em 25 repetições. Após 62 dias de cultivo as plantas foram colhidas e avaliadas. Observou-se o peso da planta e da raiz, o número de folhas e o diâmetro da cabeça. As folhas mais novas foram coletadas para análise de macro e micronutrientes. As plantas que se desenvolveram em casca de arroz apresentaram peso, tanto de planta quanto de raiz, significativamente superior ao observado nos outros dois tratamentos. Não foi observada diferença estatística significativa para peso de planta e de raiz nos tratamentos brita e seixo. Quanto ao número de folhas e diâmetro da cabeça foram observadas diferenças estatísticas significativas entre todos os tratamentos, sendo que ambos foram maiores em plantas cultivadas em casca de arroz, seguida da brita e seixo. Não houve diferença estatística significativa na absorção de macronutrientes entre os tratamentos. As plantas cultivadas em casca de arroz absorveram significativamente menos zinco e cobre que as plantas cultivadas nos outros dois substratos.

Palavras-Chave: Lactuca sativa L., hidroponia, brita, seixo, casca de arroz.

\section{ABSTRACT}

Yield response of hydroponic lettuce grown on three different substrates.

In an experiment carried out between September and November 1997 at Fazenda Água Limpa, Universidade de Brasília, Brazil, growth and yield of lettuce cultivar Verônica were evaluated on three different substrates in a hydroponic system. The experimental design was a complete randomized block with three treatments: rice husk, gravel and pebble, with 25 replicates. After 62 days, plants were collected and plant and root weight, number of leaves and head diameter were evaluated. The younger leaves from plants from all treatments were also collected for macro and micronutrients analyses. Plants grown on rice husk showed significantly higher plant and root weight compared to those grown on gravel and pebble. No statistically significant difference was observed for plant and root weight in gravel and pebble treatments. Statistically significant differences between all treatments were observed on the basis of number of leaves and head diameter. Both parameters were higher in plants grown on rice husks, followed by gravel and pebble. No differences were observed in the absorption of macronutrients amongtreatments. However, plants grown on rice husk absorbed less zinc and copper than plants grown on gravel and pebble.

Keywords: Lactuca sativa L., hydropony, gravel, pebble, rice husk.

(Aceito para publicação em 18 de setembro de 1999)

\footnotetext{
${ }^{1}$ Trabalho realizado como parte das exigências para obtenção do grau de Engenheiro Agrônomo pelo primeiro autor.
} 
$\mathrm{H}_{\mathrm{a}}^{\mathrm{i}}$ idroponia é o nome dado a todas as formas de cultivo em solução nutritiva sem uso do solo. O termo hidroponia deriva de duas palavras gregas: hidro, água e ponos, trabalho. A combinação destas duas palavras significa "trabalhar com a água", e implicitamente, o uso de soluções de adubos químicos para o cultivo de plantas na ausência do solo (Douglas, 1987; Castellane \& Araujo, 1995).

A hidroponia vem se tornando uma alternativa bastante interessante em relação ao cultivo tradicional feito no solo. Ela pode ser usada em regiões em que há pouca disponibilidade de terras agricultáveis e em regiões onde ocorreu um uso excessivo do solo, causando desequilíbrio em sua microfauna, aumentando o nível de infestação de patógenos de solo, problema frequente em solos sob estufa. Assim, mesmo em países tropicais com abundância de terra como o Brasil, a hidroponia tem sido utilizada com bastante êxito. Além da sua elevada capacidade de produção, independente de clima ou de solo, a hidroponia oferece ainda produtos de alta qualidade e com uso bastante reduzido de agrotóxicos, se comparada ao meio tradicional de cultivo no solo (Castellane \& Araujo, 1995; Junqueira et al., 1997).

Praticamente qualquer planta que cresça naturalmente no solo pode ser cultivada em hidroponia. Entre elas, árvores de pequeno porte, arbustos, plantas herbáceas como cereais, leguminosas, plantas ornamentais, hortaliças e outras (Crocomo, 1986).

A alface (Lactuca sativa L.), por ocupar pouco espaço, atingir mais rapidamente o ponto de comercialização e pelo rápido retorno financeiro, é a cultura que vem ganhando cada vez mais espaço na produção hidropônica (Zito et al., 1994).

Existem diversos sistemas hidropônicos. Um dos mais utilizados é o NFT (Nutrient Film Technique) onde a planta absorve os nutrientes diretamente de um filme de água que passa pelas suas raízes. Apesar deste método apresentar algumas vantagens como o de ser desfavorável ao desenvolvimento de algas e à salinização, este sistema apresenta a desvantagem de exigir um tempo de repou- so muito curto e um alto consumo de energia (Castellane \& Araujo, 1995; Martinez \& Silva Filho, 1997).

O desenvolvimento de técnicas que reduzam o consumo de energia em hidroponia é de fundamental importância, pois com isso haverá uma redução no custo de produção (Tavares, 1997). Umas destas técnicas é o sistema NFTmodificado. Neste sistema são utilizados substratos que permitam uma retenção maior da umidade e uma diminuição no consumo de energia. No entanto existe uma limitação para seu uso que é o de não se conhecer ainda os substratos que apresentam as melhores condições para a produção hidropônica de plantas.

No presente trabalhou procurou-se avaliar entre três substratos: brita, seixo de rio e casca de arroz ao natural, qual seria o mais apropriado para o cultivo de alface no sistema NFT-modificado.

\section{MATERIAL E MÉTODOS}

$\mathrm{O}$ experimento foi instalado em uma casa de vegetação na Fazenda Água Limpa da Universidade de Brasília, localizada no Núcleo Rural Vargem Bonita (DF), no período de setembro a novembro de 1997.

O delineamento experimental utilizado foi inteiramente casualizado com três tratamentos: casca de arroz, brita e seixo em 25 repetições, utilizando-se o sistem NFT-modificado. Os substratos foram esterilizados com uma solução à base de hipoclorito de sódio a $5 \%$.

O sistema hidropônico era composto de um depósito de solução, de um conjunto moto-bomba, bancada e canais para circulação da solução nutritiva, de canos para o transporte da solução até os canais e retorno até o depósito e um temporizador.

A solução nutritiva foi preparada conforme recomendação da Embrapa Hortaliças (Junqueira et al., 1997) com a seguinte formulação para 1.000 litros: $550 \mathrm{~g}$ de sulfato de magnésio, $950 \mathrm{~g}$ de nitrato de cálcio, $810 \mathrm{~g}$ de nitrato de potássio, $115 \mathrm{~g}$ de monofosfato de amônio, 3,0 g de ácido bórico, 0,2 $\mathrm{g}$ de molibdato de sódio, 2,0 g de sulfato de manganês, $0,15 \mathrm{~g}$ de sulfato de cobre, $0,2 \mathrm{~g}$ de sulfato de zinco e $60 \mathrm{~g}$ de ferro EDTA - Ferrilene.
$\mathrm{Na}$ fase de berçário foi utilizada solução nutritiva com $50 \%$ de concentração de sais. Quando as plantas foram transferidas para o leito definitivo utilizou-se solução completa.

Trabalhou-se com a cultivar Verônica devido à sua boa adaptação em cultivos feitos no verão. As mudas foram produzidas em bandejas de isopor com substrato artificial à base de vermiculita e foram transplantadas para o berçário com 22 dias. O berçário era composto por 12 canais e a cada quatro canais foi colocado um substrato diferente. $\mathrm{O}$ espaçamento das plantas no berçário era de $5 \mathrm{~cm} \times 5 \mathrm{~cm}$ e o número de plantas por substrato era de 80 , totalizando 240 plantas na bancada. A vazão no canal era de 1,5 litros por minuto e o tempo de funcionamento e de repouso foram ajustados conforme a necessidade da planta, sendo 15 minutos de funcionamento e 45 minutos desligado no período diurno (8 às 18 horas) e 15 minutos de funcionamento e uma hora de repouso durante o período noturno (18 às 8 horas). Isto foi usado para os primeiros dois dias de cultivo, pois as plantas estavam em fase de adaptação. No terceiro dia de cultivo o tempo de repouso passou para uma hora durante o dia e duas horas durante a noite, sendo que o tempo de funcionamento permaneceu o mesmo. $\mathrm{O} \mathrm{pH}$ da solução foi mantido no intervalo de 6,0 a 6,5 sendo monitorado com peagâmetro. As plantas permaneceram no berçário por treze dias e foram transplantadas para o leito definitivo com quatro folhas completamente desenvolvidas.

No leito definitivo as plantas foram dispostas em um espaçamento de $25 \mathrm{x}$ $25 \mathrm{~cm}$. Foram transplantadas 31 plantas por substrato, totalizando 93. A vazão dos canais foi de 2,0 litros por minuto e o tempo de funcionamento do conjunto moto-bomba, assim como no berçário, foi ajustado conforme as necessidades da planta ao longo do ciclo. Assim, no primeiro dia o sistema foi ligado por 15 minutos, ficando desligado por $45 \mathrm{mi}-$ nutos durante o dia $\mathrm{e}$, à noite ficou funcionando por 15 minutos e por uma hora ficou desligado. Foi utilizado um tempo mais curto para que as plantas se adaptassem ao novo ambiente. Depois de 24 horas o tempo de repouso foi al- 
terado para 2 horas durante o dia e 3 horas durante a noite, o que permaneceu durante todo o restante do ciclo.

Após 62 dias, 25 plantas foram colhidas ao acaso em cada substrato. Para cada planta avaliou-se o peso da planta, o peso da raiz, número de folhas e o diâmetro da cabeça. As folhas mais novas foram coletadas para a análise dos macro e dos micronutrientes presentes em sua composição. Foi efetuada análise de variância e os dados foram comparados pelo teste Tukey a $5 \%$ de probabilidade.

\section{RESULTADOS E DISCUSSÃO}

Não houve diferença estatística significativa entre os tratamentos seixo e brita quanto ao peso da planta e peso da raiz (Tabela 1). No entanto, para ambos os parâmetros, os valores observados nas plantas cultivadas em casca de arroz foram estatisticamente superiores aos valores observados em plantas cultivadas no outros substratos.

Foi observada diferença estatística significativa entre todos os tratamentos no número de folhas e diâmetro da cabeça, sendo que para ambos os parâmetros os maiores valores foram observados nas plantas cultivadas em casca de arroz, seguida das plantas cultivadas em brita e seixo.

No tratamento com casca de arroz, onde observou-se que a alface apresentou maior peso $(119,6 \mathrm{~g})$, constatou-se que este peso foi inferior ao obtido por Horino et al. (1993) para a mesma cultivar, que foi de 169,2 g e 17,8 folhas por planta; e inferior ao relatado por Vaz (1997), que obteve para a mesma cultivar o peso de 183,40 g. Em ambos experimentos as plantas foram cultivadas diretamente em solução nutritiva.

As plantas de alface cultivadas nos diferentes substratos não apresentaram diferença estatística significativa na absorção de macronutrientes (Tabela 2). No entanto, foi observada diferença estatística significativa na absorção dos micronutrientes cobre e zinco (Tabela 3). As plantas cultivadas em casca de arroz apresentaram teor de zinco e cobre inferior ao observado nas plantas cultivadas em brita e seixo.

Tabela 1. Peso médio das plantas e raízes (g), número médio de folhas e diâmetro médio da planta de alface $(\mathrm{cm})$ cultivadas em sistema hidropônico utilizando três diferentes substratos. Brasília, UnB, 1997.

\begin{tabular}{|c|c|c|c|}
\hline Parâmetros & $\begin{array}{c}\text { Casca de } \\
\text { arroz }\end{array}$ & Brita & Seixo \\
\hline Peso médio das plantas & 119,60a* & $39,40 b$ & $23,40 b$ \\
\hline Peso médio das raízes & $58,20 a$ & $28,80 \mathrm{~b}$ & $27,72 b$ \\
\hline Número médio de folhas por planta & $18,68 a$ & $12,16 \mathrm{~b}$ & 9,52 \\
\hline Diâmetro médio da cabeça & $34,72 a$ & $22,92 b$ & 17,96 \\
\hline
\end{tabular}

*As médias seguidas pela mesma letra na vertical não diferem entre si pelo teste de Tukey $(\mathrm{P}<0,05)$.

Tabela 2. Teores médios de macronutrientes encontrados em folhas de alface sob cultivo hidropônico utilizando três diferentes substratos (g.Kg $\mathrm{Kg}^{-1}$ do peso seco). Brasília, UnB, 1997.

\begin{tabular}{lccr}
\hline \multicolumn{1}{c}{ Parâmetros } & Casca de arroz & Brita & Seixo \\
\hline Nitrogênio & $23,50 a^{*}$ & $23,50 a$ & $24,50 a$ \\
Fósforo & $1,50 a$ & $1,45 a$ & $1,55 a$ \\
Potássio & $9,25 a$ & $9,75 a$ & $7,75 a$ \\
Cálcio & $3,20 a$ & $4,00 a$ & $2,75 a$ \\
Magnésio & $0,80 a$ & $0,50 a$ & $0,60 a$ \\
Enxofre & $0,65 a$ & $0,60 a$ & $0,70 a$ \\
\hline
\end{tabular}

* As médias seguidas pela mesma letra na vertical não diferem entre si pelo teste de Tukey $(\mathrm{P}<0,05)$.

Tabela 3. Teores médios de micronutrientes encontrados em folhas de alface sob cultivo hidropônico utilizando três diferentes substratos (mg. $\left.\mathrm{Kg}^{-1}\right)$. Brasília, UnB, 1997.

\begin{tabular}{lccc}
\hline \multicolumn{1}{c}{ Parâmetros } & Casca de arroz & Brita & Seixo \\
\hline Boro & $77,10 a^{*}$ & $119,80 \mathrm{a}$ & $173,75 \mathrm{a}$ \\
Zinco & $52,30 \mathrm{~b}$ & $121,50 \mathrm{a}$ & $97,25 \mathrm{ab}$ \\
Ferro & $237,00 \mathrm{a}$ & $285,00 \mathrm{a}$ & $305,25 \mathrm{a}$ \\
Manganês & $271,50 \mathrm{a}$ & $300,50 \mathrm{a}$ & $200,00 \mathrm{a}$ \\
Cobre & $6,30 \mathrm{~b}$ & $12,85 \mathrm{a}$ & $13,95 \mathrm{a}$ \\
Cobalto & $1,11 \mathrm{a}$ & $2,22 \mathrm{a}$ & $1,89 \mathrm{a}$ \\
Molibdênio & $95,25 \mathrm{a}$ & $145,00 \mathrm{a}$ & $71,05 \mathrm{a}$ \\
Sódio & $385,00 \mathrm{a}$ & $385,00 \mathrm{a}$ & $437,50 \mathrm{a}$ \\
\hline
\end{tabular}

* As médias seguidas pela mesma letra na vertical não diferem entre si pelo teste de Tukey $(\mathrm{P}<0,05)$.

Segundo Malavolta (1989) os teores ideais dos macronutrientes encontrados em folhas de alface cultivado em solo são: $\mathrm{N}=30,0$ g. $\mathrm{Kg}^{-1} ; \mathrm{P}=3,50 \mathrm{~g} . \mathrm{Kg}$ ${ }^{1} ; \mathrm{K}=50,0 \mathrm{~g} \cdot \mathrm{Kg}^{-1} ; \mathrm{Ca}=12,50 \mathrm{~g} \cdot \mathrm{Kg}^{-1}$; $\mathrm{Mg}=3,50 \mathrm{~g} \cdot \mathrm{Kg}^{-1}$ e $\mathrm{S}=2,0 \mathrm{~g} . \mathrm{Kg}^{-1}$. Raji (1996) apresenta como parâmetro ideal para os micronutrientes os seguintes valores: $\mathrm{Bo}=30$ a $60 \mathrm{mg} \cdot \mathrm{Kg}^{-1} ; \mathrm{Cu}=7$ a 20 mg. $\mathrm{Kg}^{1} ; \mathrm{Fe}=50$ a $150 \mathrm{mg} \cdot \mathrm{Kg}^{1} ; \mathrm{Mn}$ $=30$ a $150 \mathrm{mg} \cdot \mathrm{Kg}^{-1}$ e $\mathrm{Zn}=30$ a 100 mg. $\mathrm{Kg}^{-1}$. A deficiência de alguns dos nutrientes observada na análise foliar das plantas de alface colhidas neste experimento pode estar relacionada à concentração e disponibilidade da solução nutritiva durante o ciclo da cultura.

Verificou-se que o substrato casca de arroz permaneceu úmido por tempo superior ao observado nos outros dois substratos. Porém, mesmo assim, observou-se deficiência de vários nutrientes nas plantas desenvolvidas em casca de arroz, sugerindo que a solução nutritiva 
preparada não continha a quantidade necessária de nutrientes para a cultura da alface, tendo sido, provavelmente, a causa do baixo peso da alface em todos os tratamentos. O tempo de contato entre a solução nutritiva e as raízes nos tratamentos brita e seixo foi, provavelmente, inferior ao observado em casca de arroz, contribuindo para acentuar a deficiência nutricional e os baixos pesos observados. É possível que um ajuste na concentração da solução nutritiva, bem como no tempo de funcionamento e de repouso do sistema motobomba, de maneira que a solução nutritiva possa permanecer por mais tempo nas bancadas, possa vir a contribuir para um aumento de peso da cabeça de alface produzida em brita e seixo.

\section{AGRADECIMENTOS}

Os autores agradecem ao PIBIC-UnB/ $\mathrm{CNPq}$, pela concessão de bolsa, ao Professor Tsuneharu Kaneshiro e ao Agrônomo Eity Kato da Faculdade de Agro- nomia e Medicina Veterinária da Universidade de Brasília, pela colaboração na instalação do sistema hidropônico, aos funcionários da Fazenda Água Limpa, Robson Figueiredo Cunha, Benevaldo Ferreira Quadro, Íris Pereira Júnior, Raimundo Luiz Sampaio e Ronaldo da Silva Costa, pela contribuição prestada durante a realização do experimento e, ao Dr Renato Fernando Amabile, pela criteriosa revisão do manuscrito.

\section{LITERATURA CITADA}

CASTELlANE, P.D.; ARAUJO, J.A.C. de. $\mathrm{Cul}$ tivo sem solo - hidroponia. Jaboticabal, FUNEP, 1995. $43 \mathrm{p}$.

CROCOMO, O.J. Cultivo fora do solo: hidroponia. In: MAGALHÃES, A; BORDINI, M. da E. ed. Grande manual globo de agricultura, pecuária e receituário industrial. Porto Alegre: vol. III, 1986. 209-220 p.

DOUGLAS, J.S. Hidroponia: cultura sem terra. São Paulo: Nobel , 1987. 141p.

HORINO, Y.; MELO, P.E. de; Makishima, N Comportamento de quatro cultivares de alface desenvolvidas sob hidroponia. Ensaio preliminar. Horticultura Brasileira, Brasília, v. 11, n. 1, p. 76, 1993. (Resumo).
JUNQUEIRA, A..M.R.; LIMA, J.A.; PEIXOTO, J.R. Hidroponia: cultivo sem solo. Brasília: UnB, Curso de Extensão da Faculdade de Agronomia e Medicina Veterinária, 1997. 31 p.

MALAVOLTA, E. ABC da Adubação. $5^{\mathrm{a}}$ ed. São Paulo: Ceres, 1989. 292 p.

MARTINEZ, H.E.P.; SILVA FILHO, J.B. Introdução ao sistema hidropônico de plantas. Viçosa: UFV, 1997. 52 p.

RAJI, B. VAN. Recomendações de adubação $e$ calagem para o estado de São Paulo, Campinas: IAC, Boletim Técnico n 100, 1996. 285 p.

TAVARES, H.L. Produção hidropônica de alface cv. Verônica em diferentes substratos. Brasília: UnB, 1997. 54 p. (Dissertação graduação).

VAZ, R. M. R. Comportamento de Três Cultivares de Alface sob Cultivo Hidropônico: Brasília: UnB, 1997. 30 p. (Dissertação graduação).

ZITO, R.K.; FRONZA, V.; MARTINEZ, H.E.P.; PEREIRA, P.R.G.; FONTES, P.C.R. Fontes de nutrientes, relações nitrato: amônio e molibdênio, em alface (Lactuca sativa $L$ ) produzida em meio hidropônico. Revista Ceres, Viçosa, v. 41, n. 236, 1994, p. 419-430. 